\title{
Experimental investigation of thermal emittance components of copper photocathode
}

\author{
H. J. Qian, C. Li, Y. C. Du, L. X. Yan, J. F. Hua, W. H. Huang, and C. X. Tang* \\ Department of Engineering Physics, Tsinghua University, Beijing, 100084, China
}

(Received 25 December 2011; published 30 April 2012)

\begin{abstract}
With progress of photoinjector technology, thermal emittance has become the primary limitation of electron beam brightness. Extensive efforts have been devoted to study thermal emittance, but experiment results differ between research groups and few can be well interpreted. Besides the ambiguity of photoemission mechanism, variations of cathode surface conditions during cathode preparation, such as work function, field enhancement factor, and surface roughness, will cause thermal emittance differences. In this paper, we report an experimental study of electric field dependence of copper cathode quantum efficiency (QE) and thermal emittance in a radio frequency (rf) gun, through which in situ cathode surface parameters and thermal emittance contributions from photon energy, Schottky effect, and surface roughness are extracted. It is found the QE of a copper cathode illuminated by a $266 \mathrm{~nm}$ UV laser increased substantially to $1.5 \times 10^{-4}$ after cathode cleaning during rf conditioning, and a copper work function of $4.16 \mathrm{eV}$, which is much lower than nominal value $(4.65 \mathrm{eV})$, was measured. Experimental results also show a thermal emittance growth as much as $0.92 \mathrm{~mm} \mathrm{mrad} / \mathrm{mm}$ at $50 \mathrm{MV} / \mathrm{m}$ due to the cathode surface roughness effect, which is consistent with cathode surface morphology measurements.
\end{abstract}

DOI: 10.1103/PhysRevSTAB.15.040102

PACS numbers: 29.25.Bx, 29.27.Fh

\section{INTRODUCTION}

Photoinjector technology has witnessed enormous improvements during the past decade [1-6] and its sensational beam brightness has enabled the success of linac coherent light sources (LCLS) [7], the first hard x-ray free electron laser, and many other light sources $[8,9]$. With interests growing on compact and high duty factor free electron laser light sources $[10,11]$, both peak and average beam brightness of photoinjector need further upgrade. While the average beam brightness relies on high average power laser system and high quantum efficiency $(\mathrm{QE})$ photocathodes [12], the peak beam brightness is limited by the rf gun acceleration gradient and thermal emittance [13]. The acceleration gradient is boosted by moving to higher frequencies, such as X-band and C-band [14,15], and a gradient of $200 \mathrm{MV} / \mathrm{m}$ has been realized in an $\mathrm{X}$-band $\mathrm{rf}$ gun [14], which is predicted by simulation to deliver an electron beam with beam brightness a factor of $\sim 5$ higher than that from the LCLS photoinjector [16]. Thermal emittance depends on a lot of factors, and first of all the photoemission mechanism, surface photoemission, or volume photoemission [17]. Surface photoemission mediated by a $p$ polarized laser or surface plasmon is expected to enhance the cathode $\mathrm{QE}$ and meanwhile keep a small thermal emittance [18-21], which is

\footnotetext{
*tang.xuh@mail.tsinghua.edu.cn

Published by the American Physical Society under the terms of the Creative Commons Attribution 3.0 License. Further distribution of this work must maintain attribution to the author(s) and the published article's title, journal citation, and DOI.
}

ideal for photoinjector cathode. The volume photoemission cathode, as the current workhorse of photoinjectors, is extensively studied [12]. Volume photoemission thermal emittance depends on photon energy, cathode work function, Schottky effect, and surface roughness [22-26], and it was proposed to minimize the thermal emittance by matching the photon energy with the effective work function at the sacrifice of $\mathrm{QE}$ [27,28].

Experimental studies of photoemission emittance are rich but diverge between research groups, and few can be well interpreted [12], even for the most commonly studied copper cathode $[6,29]$. One possibility for thermal emittance data divergence is the variations of cathode surface conditions, such as work function, field enhancement factor, and surface roughness, which may be caused by different cathode preparation techniques and working conditions. The uncertainties of work function and field enhancement factor will cause variations in both QE and thermal emittance. Surface roughness not only increases the field enhancement factor, but also introduces a transverse electric field that increases the transverse energy of the electron, which finally causes thermal emittance growth [24-26]. In this paper, electric field dependence of QE and thermal emittance of copper are measured in a photocathode $\mathrm{rf}$ gun, and thermal emittances contributed by the gap between photon energy and work function, Schottky effect, and surface roughness are numerically fitted, which in turn extract work function and field enhancement factor. The rest of this paper is organized as follows: Section II explains the models of QE and thermal emittance. Section III 
introduces the experiment setup and beam parameter optimizations. Section IV presents the experiment results and discussions.

\section{MODEL OF QE AND THERMAL EMITTANCE}

The QE of a metal photocathode near the photoemission threshold can generally be expressed in the following form [22]:

$$
\mathrm{QE}=\frac{1-R(\omega)}{1+\frac{\lambda_{\mathrm{opt}}(\omega)}{\lambda_{e-e}(\omega)}} \frac{E_{F}+\hbar \omega}{2 \hbar \omega}\left(1-\sqrt{\frac{E_{F}+\phi_{\mathrm{eff}}}{E_{F}+\hbar \omega}}\right)^{2},
$$

where $\hbar \omega$ is photon energy, $\phi_{\text {eff }}$ is effective work function, $E_{F}$ is Fermi energy, $R$ is laser reflection, $\lambda_{\text {opt }}$ is laser absorption length, and $\lambda_{e-e}$ is electron-electron scattering mean-free path. In most cases of photoinjector, photon energy is kept constant, and $\phi_{\text {eff }}$ is varied in a small range due to Schottky effect. When $\hbar \omega$ is near $\phi_{\text {eff }}$, Eq. (1) can be approximated as

$$
\mathrm{QE}=A\left(\frac{\hbar \omega-\phi_{w}}{e \sqrt{e \beta /\left(4 \pi \varepsilon_{0}\right)}}+\sqrt{E}\right)^{2}=A(p+\sqrt{E})^{2},
$$

where $\phi_{w}$ is work function, $\beta$ is field enhancement factor, and $E$ is the electric field at cathode. Numerical calculations show coefficient $A$ is insensitive to $E$ between 10 and $100 \mathrm{MV} / \mathrm{m}$, and $\sqrt{\mathrm{QE}}$ is linearly proportional to $\sqrt{E}$, so $p$ can be extracted by measuring electric field dependence of QE. The gap between photon energy and work function can be evaluated by the Schottky effect, as in Eq. (3), which gives an upper limit of cathode work function:

$$
\hbar \omega-\phi_{w}=e \sqrt{\frac{e \beta}{4 \pi \varepsilon_{0}}} p \geq e \sqrt{\frac{e}{4 \pi \varepsilon_{0}}} p .
$$

Equation (3) is numerically tested on a copper model with parameters shown in Table I of Ref. [22]. The field enhancement factor is assumed to be one, and electric field is varied between 10 and $60 \mathrm{MV} / \mathrm{m}$. QE is calculated by Eq. (1), and $p$ is linearly fitted according to the model of Eq. (2). The work function calculated by Eq. (3) is $4.35 \mathrm{eV}$, which is very close to the set value of $4.31 \mathrm{eV}$.

Within the 3-step model theory for volume photoemission [22], the thermal emittance due to excessive photon energy is formulated in Eq. (4),

$$
\frac{\varepsilon_{\text {th }}}{\sigma_{\text {laser }}}=\sqrt{\frac{\hbar \omega-\phi_{w}+e \sqrt{e \beta E /\left(4 \pi \varepsilon_{0}\right)}}{3 m c^{2}}},
$$

where $\sigma_{\text {laser }}$ is rms laser spot size on the cathode. Considering the copper example in Table I of Ref. [22], Eq. (4) predicts a thermal emittance of $0.73 \mathrm{~mm} \mathrm{mrad} / \mathrm{mm}$.

The practical cathode has surface roughness, and the roughness induced emittance growth has been theoretically studied in many papers [24-26]. Considering a simplified two dimensional (2D) roughness model, as in Eq. (5),

$$
z=a \cos \left(2 \pi \frac{x}{\lambda}\right)
$$

where $a$ is roughness amplitude and $\lambda$ is roughness period. Because of surface roughness, the local surface normal direction is divergent relative to the macrocathode surface, so is the electron emission angle and electric field terminated on the surface, which increase transverse energy of the electrons and thus the thermal emittance. The total thermal emittance after considering the emission angle diffusion due to the microsurface roughness is

$$
\frac{\varepsilon_{2 \mathrm{D}, \text { roughness }}^{\text {angle }}}{\sigma_{\text {laser }}}=\sqrt{\frac{\left\langle p_{\text {local }, x}^{2} \cos ^{2} \theta\right\rangle+\left\langle p_{\text {local }, z}^{2} \sin ^{2} \theta\right\rangle}{m^{2} c^{2}}},
$$

where $\theta$ is the angle between the microsurface normal and macrosurface normal, $p_{\text {local }, x}$ and $p_{\text {local }, z}$ are the momenta parallel and perpendicular to the microsurface, respectively. Following Eq. (4),

$$
\begin{gathered}
\frac{\left\langle p_{\text {local }, x}^{2}\right\rangle}{m^{2} c^{2}}=\frac{\left\langle p_{\text {local }, y}^{2}\right\rangle}{m^{2} c^{2}}=\frac{\hbar \omega-\phi_{w}+e \sqrt{e \beta E /\left(4 \pi \varepsilon_{0}\right)}}{3 m c^{2}} \\
\frac{\left\langle p_{\text {local }, z}^{2}\right\rangle}{m^{2} c^{2}} \leq \frac{4\left(\hbar \omega-\phi_{w}+e \sqrt{e \beta E /\left(4 \pi \varepsilon_{0}\right)}\right)}{3 m c^{2}} .
\end{gathered}
$$

Then Eq. (6) can be written as

$$
\varepsilon_{2 \mathrm{D}, \text { roughness }}^{\text {angle }} \leq \varepsilon_{\mathrm{th}} \sqrt{1+6\left(\frac{\pi a}{\lambda}\right)^{2}},
$$

assuming a roughness pattern of $a=100 \mathrm{~nm}$ and $\lambda=$ $10 \mu \mathrm{m}$, and Eq. (6) predicts a thermal emittance increase no more than $0.3 \%$, which is negligible.

When $2 \pi / \lambda \ll 1$, the electric field near the microsurface could be approximated as [30]

$$
\begin{gathered}
E_{x}=E \frac{2 \pi a}{\lambda} e^{-2 \pi z / \lambda} \sin (2 \pi x / \lambda) \\
E_{z}=E\left(1+\frac{2 \pi a}{\lambda} e^{-2 \pi z / \lambda} \cos (2 \pi x / \lambda)\right) .
\end{gathered}
$$

Then the maximum surface enhancement factor is

$$
\beta_{\max }=1+\frac{2 \pi a}{\lambda} .
$$

Emittance growth induced by transverse electric field is formulated as $[25,26]$

$$
\frac{\Delta \varepsilon_{2 \mathrm{D}, \text { roughness }}^{E \text {-field }}}{\sigma_{\text {laser }}}=\sqrt{\frac{e \pi^{2}}{2 m c^{2}} \frac{a^{2}}{\lambda}} E .
$$

Since the transverse energy imparted to the electrons is linearly proportional to electric field intensity, the transverse momentum growth is square root proportional to $E$, as shown in Eq. (13). Assuming the same roughness pattern mentioned above and a typical gradient of $50 \mathrm{MV} / \mathrm{m}$ in the 
rf gun, Eq. (13) predicts an emittance growth of $0.69 \mathrm{~mm} \mathrm{mrad} / \mathrm{mm}$, which is remarkable. Since a practical surface roughness is more complex than Eq. (5), the emittance growth induced by transverse electric field can be formulated as

$$
\frac{\Delta \varepsilon_{\text {roughness }}^{E \text {-field }}}{\sigma_{\text {laser }}}=\sqrt{\frac{X_{g} E}{3 m c^{2}}}
$$

where $X_{g}$ is the unknown geometry factor of the roughness emittance.

Based on the above analysis, if the roughness emittance growth due to emission angle diffusion [Eq. (9)] is neglected and there is little correlation between emittances caused by photoexcitation [Eq. (4)] and roughness [Eq. (13)], the total thermal emittance is

$$
\begin{aligned}
\frac{\varepsilon_{\text {thermal }}^{\text {total }}}{\sigma_{\text {laser }}} & =\sqrt{\varepsilon_{\text {smooth }}^{2}+\left(\Delta \varepsilon_{\text {roughness }}^{E-\text {-field }}\right)^{2}} / \sigma_{\text {laser }} \\
& =\sqrt{\frac{1}{3 m c^{2}}\left(\hbar \omega-\phi_{w}+e \sqrt{\frac{e \beta}{4 \pi \varepsilon_{0}}} \sqrt{E}+X_{g} E\right)} .
\end{aligned}
$$

From Eq. (15), we can see the relationship between square of the total thermal emittance and $\sqrt{E}$ is a parabola. If the total thermal emittance is characterized as a function of $E$, work function, field enhancement factor, and roughness emittance can be numerically fitted, and this will help understand the cathode status and thermal emittance data. When the surface roughness pattern is defined, such as that in Eq. (5), field enhancement factor $\beta$ and the geometry factor $X_{g}$ are correlated, and they cannot be viewed as independent parameters. The practical roughness pattern is random, as shown later in Sec. IV, so the correlation between the field enhancement factor and the geometry factor varies with the roughness pattern. In the following, the two factors are taken as independent parameters in the thermal emittance model fitting.

It is well known that parabola fitting is very sensitive to errors if data points are not distributed at both sides of the bottom of the parabola, just like the emittance fitting in quadruple or solenoid scan. Unfortunately, direct fitting of Eq. (15) falls into the sensitive category. A simulation of such a direct fitting is done numerically, and the nominal

TABLE I. Nominal parameters of a copper cathode for thermal emittance model fitting simulation.

\begin{tabular}{lc}
\hline \hline Parameter & Value \\
\hline$\hbar \omega$ & $4.86 \mathrm{eV}$ \\
$\phi_{w}$ & $4.31 \mathrm{eV}$ \\
$\beta$ & 1.5 \\
$\frac{\Delta \varepsilon_{\text {rovelentess }}^{E-\text { fies }}}{\sigma_{\text {laser }}}$ & $0.57 \mu \mathrm{m} / \mathrm{mm}$ at $50 \mathrm{MV} / \mathrm{m}$ \\
\hline \hline
\end{tabular}

parameters are shown in Table I. Thermal emittance is assumed to be measured with laser-rf phases of 10, 20, 30,40 , and $50 \mathrm{deg}$ from zero crossing in a rf gun with peak gradient of $50 \mathrm{MV} / \mathrm{m}$, and thermal emittance values are calculated by Eq. (15), while a 5\% (rms) measurement error is added. The histogram of 10000 numerical tests is shown in Fig. 1, which is obviously no good. Except work function, the fitting results of maximum probability for field enhancement factor and surface roughness emittance are far away from the nominal values listed in Table I.

If the QE fitting [Eq. (2)] result is employed, Eq. (15) can be rewritten as

$$
\left(\frac{\varepsilon_{\text {thermal }}^{\text {total }}}{\sigma_{\text {laser }}}\right)^{2}=\frac{1}{3 m c^{2}}\left(e \sqrt{\frac{e \beta}{4 \pi \varepsilon_{0}}}(p+\sqrt{E})+X_{g} E\right) .
$$

The parameters to be fitted are left with only the field enhancement factor $\beta$ and the roughness emittance coefficient $X_{g}$, and Eq. (16) is not a pure parabola fitting anymore, thus is expected to be less sensitive to emittance error. A simulation of Eq. (16) fitting (Fig. 2) is done with the same conditions as that for Fig. 1, and the fitting results are much better with a tighter distribution around the nominal value. Besides, by adding reasonable experimental errors to $p$, the sensitivity of Eq. (16) fitting to error
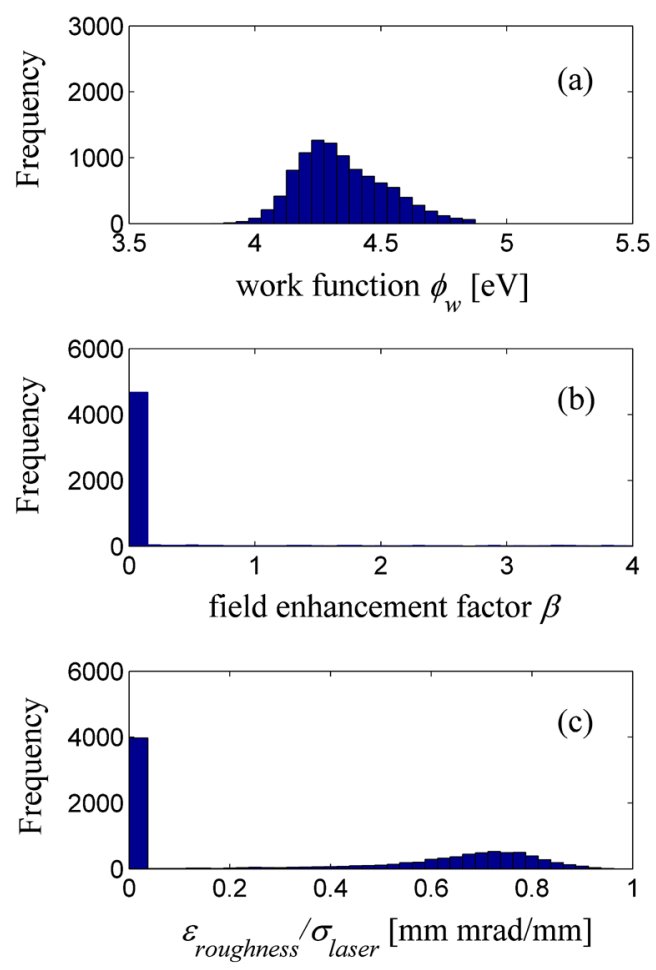

FIG. 1. $10^{4}$ simulated fitting for model of Eq. (15) with $5 \%$ (rms) emittance data error: (a) histogram of work function fitting results, (b) histogram of field enhancement factor fitting results, and (c) histogram of roughness emittance fitting results at $50 \mathrm{MV} / \mathrm{m}$. 

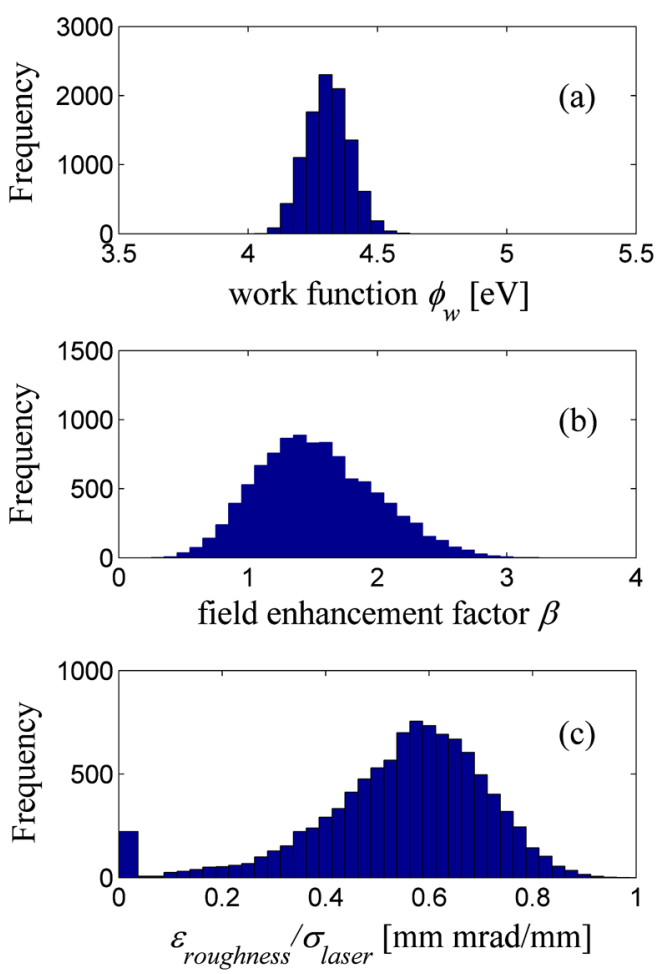

FIG. 2. $10^{4}$ simulated fitting for model of Eq. (16) with $5 \%$ (rms) emittance data error: (a) histogram of work function fitting results, (b) histogram of field enhancement factor fitting results, and (c) histogram of roughness emittance fitting results at $50 \mathrm{MV} / \mathrm{m}$.

of $p$ is found to be low. In the following sections, Eq. (16) will be applied in a thermal emittance model fitting experiment.

\section{EXPERIMENT SETUP AND OPTIMIZATION}

Tsinghua University has been developing Thomson scattering $\mathrm{x}$-ray sources, and a $\sim 45 \mathrm{MeV}$ photoinjector was built, which consists of a Brookhaven National Lab type S-band rf gun, a Stanford Linear Accelerator Center type 3 meter traveling wave linac, and a terawatt Ti:sapphire laser system [31]. The thermal emittance measurement was done at the front end of the Thomson scattering beam line (Fig. 3), and electron beam is generated by a near normal incident UV laser $(266 \mathrm{~nm})$ on a copper cathode. Beam charge is measured with a Faraday cup, and thermal emittance is measured by a solenoid scan technique [29,32], which consists of the combination of the gun solenoid and a YAG screen (100 $\mu \mathrm{m}$ thick) $105 \mathrm{~cm}$ downstream the cathode.

Photocathode rf gun emittance consists of thermal emittance, rf emittance, and space charge emittance [33], and in order to measure thermal emittance at gun exit by solenoid scan, both rf and space charge emittance have to be reduced. For space charge emittance reduction, the

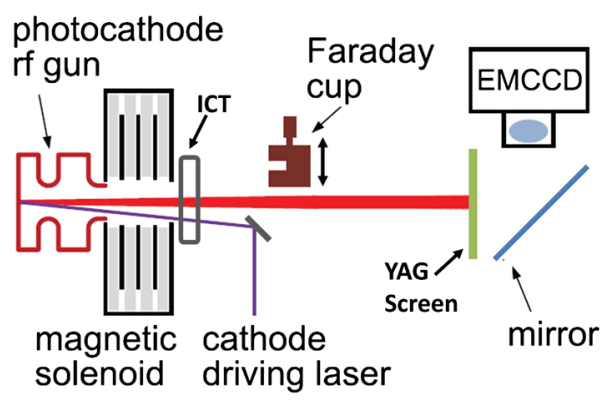

FIG. 3. Thermal emittance measurement setup.

electron beam charge was lowered below $1 \mathrm{pC}$ [32], thus a background noise formed by high dark current of our gun is comparable to photoelectron beam profile intensity, which leads to an overestimation of electron beam size. Since dark current is exponentially dependent on electric field [34], the peak gun gradient was lowered from 75 to $40 \mathrm{MV} / \mathrm{m}$ during thermal emittance measurement, and the dark current noise is reduced significantly. Besides, the average energy of dark current is lower than the photoelectrons, and the interference of dark current with photoelectron beam size measurement exists when dark current is focused on the YAG screen, so solenoid strength is kept away from this region as much as possible during emittance measurement.

The rf effect induced emittance growth is squarely dependent on bunch length [33], and the actual growth with UV laser pulse length is studied by ASTRA simulations [35], which show a pulse length less than 1 ps (FWHM) will hold the maximum rf emittance growth at $40 \mathrm{deg}$ gun phase less than 5\%. A UV pulse length of $\sim 100 \mathrm{fs}$ (FWHM) is employed in our experiment and accordingly beam charge is lowered to $\sim 0.1 \mathrm{pC}$ to reduce the space charge effect. The experiment parameters are summarized in Table II.

To facilitate such a low charge experiment, a high sensitivity electron multiplying (EM) CCD camera is employed for beam profile imaging [36]. The EMCCD features large EM gain (1-1000), 16-bit digitization, and low read noise $\left(<1 e^{-}\right)$, which enables imaging of a large dynamic range and is ideal for low charge beam profile imaging.

TABLE II. Thermal emittance experiment settings.

\begin{tabular}{ll}
\hline \hline Parameter & Value \\
\hline UV wavelength & $266 \mathrm{~nm}$ \\
UV distribution & Gaussian \\
UV spot size (rms) & $0.2-0.4 \mathrm{~mm}$ \\
UV pulse length (FWHM) & $\sim 100 \mathrm{fs}$ \\
Beam charge & $\sim 0.1 \mathrm{pC}$ \\
rf gun gradient & $40 \mathrm{MV} / \mathrm{m}$ \\
rf gun phase & $10-40$ degree \\
\hline \hline
\end{tabular}




\section{EXPERIMENT RESULTS AND DISCUSSIONS}

The experiment was conducted in May and August of 2011; in between the gun vacuum was degraded due to improper vacuum restore after a new part installation at the gun exit region. After the vacuum accident, $\mathrm{rf}$ breakdowns occurred frequently when the gun operated at $\sim 75 \mathrm{MV} / \mathrm{m}$ with $10 \mathrm{~Hz}$ repetition rate. The gun was rf conditioned for about one month before the original performance was restored.

\section{A. QE measurement}

QE was measured before and after the vacuum accident, but QE dependence on the electric field was only measured after the accident. The QE data and fitting to Eq. (2) is shown in Fig. 4. The copper cathode QE rose by a factor of $\sim 3.5$ to $10^{-4}$ after gun conditioning, which is the highest QE reported at this wavelength for a copper cathode [37]. The increase of the cathode QE during gun conditioning is also observed in other groups [5,38], which indicates gun conditioning along with $\mathrm{rf}$ breakdowns or high intensity UV laser illumination on the cathode has similar effects as ion cleaning or laser cleaning [37,39]. The QE fitting to Eq. (2) shows $p=$ $12.2 \pm 1.3(\mathrm{MV} / \mathrm{m})^{1 / 2}$, and this means the upper limit of $\phi_{w}$ is $4.20 \pm 0.05 \mathrm{eV}$ after the cathode cleaning. The work function upper limit is much lower than the nominal $4.65 \mathrm{eV}$ of polycrystalline copper [40], and a similar phenomenon was reported for both copper and other metals after ion cleaning [37,40,41]. It is well known that the work function is sensitive to crystal structure and perfection, and ion bombardment damage can produce work function reduction on the order of several hundred meV $[40,41]$. The low work function in our experiment may be caused by the aggressive ion bombardment during rf breakdowns, and is also supported by the highest QE for copper measured at this wavelength [37].

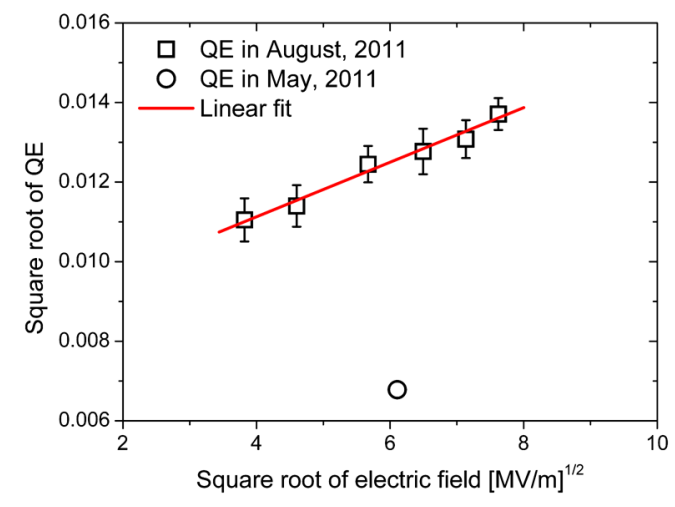

FIG. 4. QE before and after the vacuum accident.

\section{B. Thermal emittance measurement and model fitting}

Emittance fitting is sensitive to beam size calculation, and different methods for beam profile image processing, such as background noise subtraction and beam tail cutting, have been developed, out of which emittance results could differ as much as 50\% [42]. In this paper, the beam size calculation algorithm for both electron and UV laser is similar to that used at LCLS, and a 5\% area cutoff beam profile is applied [5].

The thermal emittance was compared before and after the vacuum accident, and a thermal emittance increase following the QE change was observed. As shown in Fig. 5, thermal emittance increased from 0.83 to $0.95 \mathrm{~mm} \mathrm{mrad} / \mathrm{mm}$ at a gradient of $25.7 \mathrm{MV} / \mathrm{m}$.

After QE increase, thermal emittances corresponding to different electric fields were measured by changing the photoemission gun phase (Fig. 6), and fitting of Eq. (16) extracted cathode parameters, as shown in Table III. The fitting results show the online copper work function $(4.16 \mathrm{eV})$ is much lower than its nominal value $(4.65 \mathrm{eV})$, and the thermal emittance at $50 \mathrm{MV} / \mathrm{m}$ $(1.17 \mathrm{~mm} \mathrm{mrad} / \mathrm{mm})$ is mainly contributed by roughness emittance $(0.92 \mathrm{~mm} \mathrm{mrad} / \mathrm{mm})$.

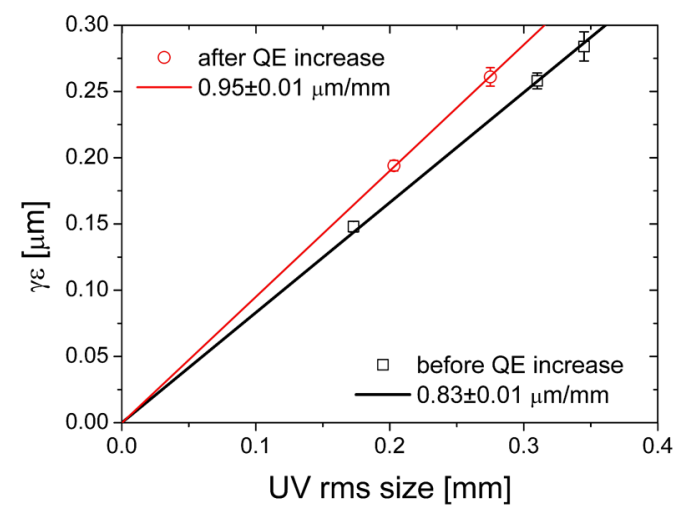

FIG. 5. Thermal emittance increase following QE change at $25.7 \mathrm{MV} / \mathrm{m}$.

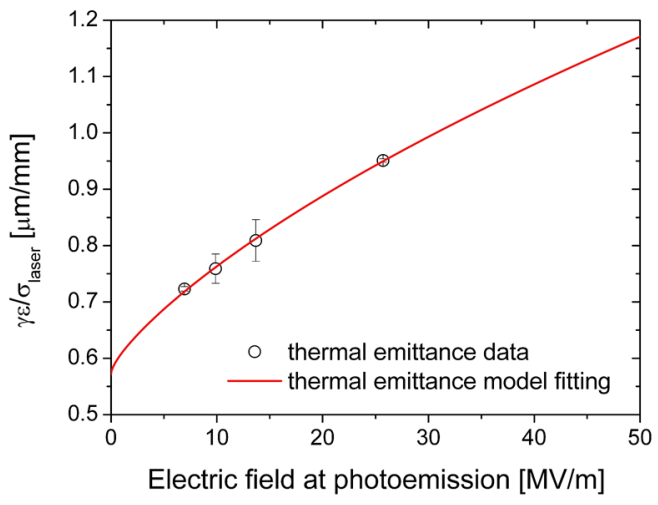

FIG. 6. Fitting of thermal emittance model by Eq. (16). 


\section{Cathode surface morphology measurement and analysis}

The photocathode $\mathrm{rf}$ gun was removed from the Thomson scattering beam line during a gun upgrade in March 2012, and the cathode was taken out for examination. The cathode surface is finished by off-axis diamond turning, and the cathode center was mirrorlike when put into the gun. After over three years of operation, the cathode center has been damaged, and surface defects are visible. A similar phenomenon was also observed for the first cathode of the LCLS gun [43]. The more detailed surface morphology measured by the white light interferometer is shown in Fig. 7, and shows nonuniform surface damage distribution. The typical undamaged surface, such as Fig. 7(d), shows an rms roughness of $36.5 \mathrm{~nm}$, and the typical damaged surface, such as Fig. 7(c), shows an rms roughness of $1420 \mathrm{~nm}$, which is a factor of 39 larger. For a first order analysis of the cathode roughness effect by Eqs. (12) and (13), surface heights along the dashed line of Figs. 7(c) and 7(d) are lined out, and Fourier analysis gives the spatial frequencies and corresponding amplitudes, which were used to calculate field enhancement factor and roughness emittance growth, as shown in Figs. 8 and 9. For the damaged surface (Fig. 8), the field enhancement factor is between 1 and 1.2, and the roughness emittance is between 0 and $3.5 \mathrm{~mm} \mathrm{mrad} / \mathrm{mm}$. For the undamaged surface (Fig. 8), the field enhancement factor is between 1 and 1.01, and the roughness emittance is between 0 and $0.15 \mathrm{~mm} \mathrm{mrad} / \mathrm{mm}$. Compared with the thermal emittance fitting results (Table III), the roughness emittance theory predicts bigger roughness emittance for the damaged surface and smaller roughness emittance for the undamaged surface. Since the area illuminated by the UV laser consists of both damaged and undamaged
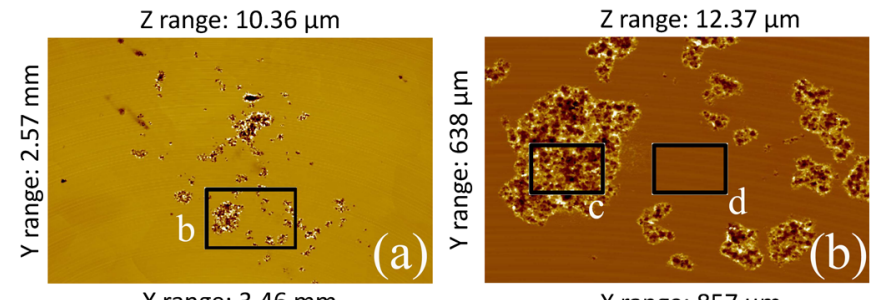

$X$ range: $3.46 \mathrm{~mm}$

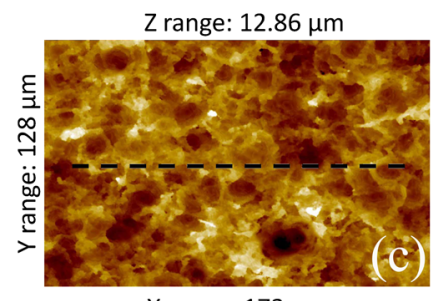

$\mathrm{X}$ range: $173 \mu \mathrm{m}$

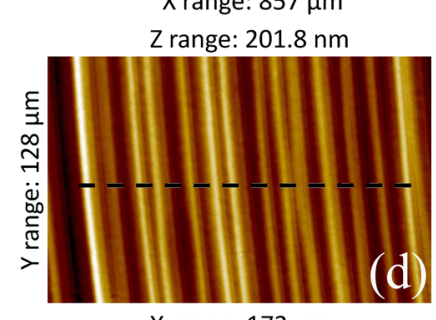

$\mathrm{X}$ range: $173 \mu \mathrm{m}$

FIG. 7. Cathode surface morphology measured by a white light interferometer, and $\mathrm{rms}$ roughnesses are (a) $233 \mathrm{~nm}$, (b) $653 \mathrm{~nm}$, (c) $1420 \mathrm{~nm}$, and (d) $36.5 \mathrm{~nm}$. surfaces, the roughness emittance should be a weighted average of the two, which is consistent with the measured roughness emittance of $0.92 \mathrm{~mm} \mathrm{mrad} / \mathrm{mm}$. The above comparison shows Eq. (13) is effective in a first order evaluation of the cathode roughness emittance.
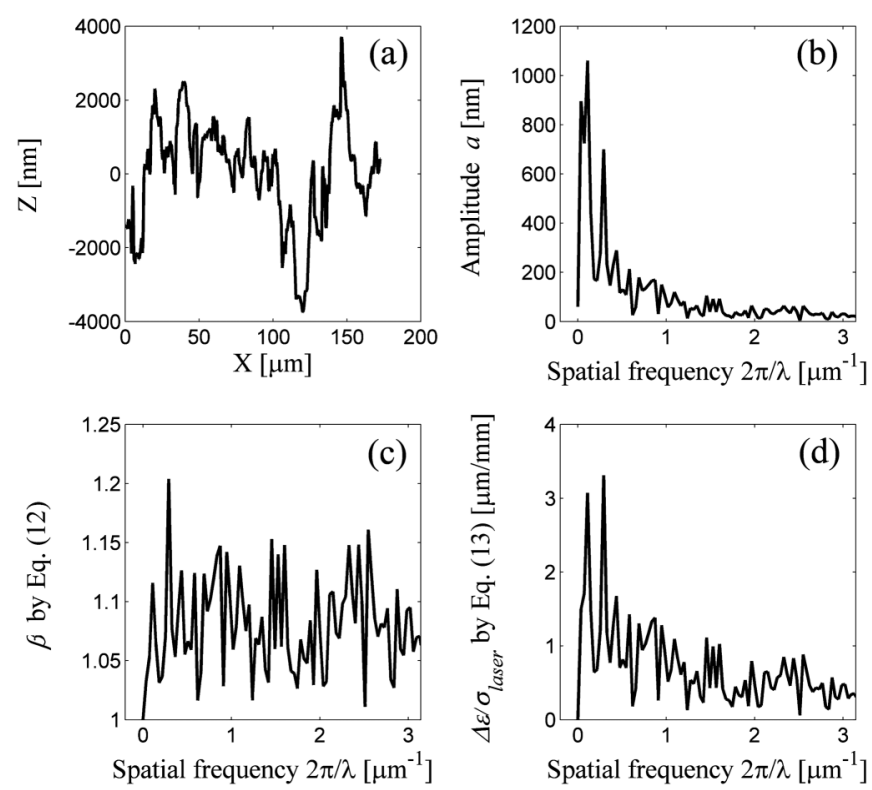

FIG. 8. Surface roughness analysis of the dashed line in Fig. 7(c): (a) surface perturbation profile, (b) spatial frequency spectrum, (c) field enhancement factor, and (d) roughness emittance growth at $50 \mathrm{MV} / \mathrm{m}$.
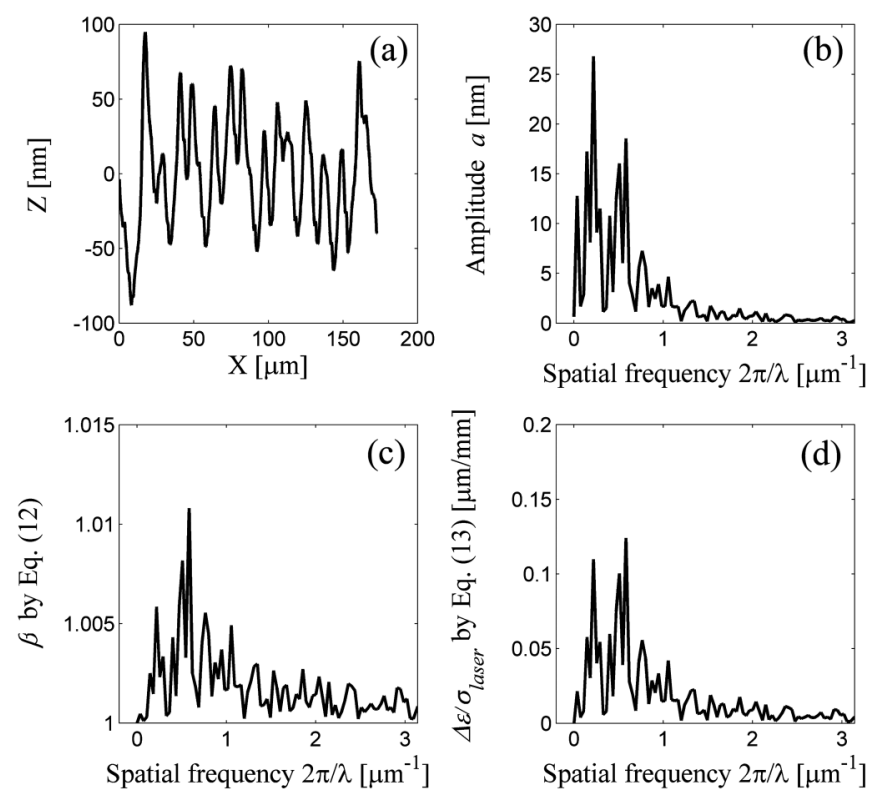

FIG. 9. Surface roughness analysis of the dashed line in Fig. 7(d): (a) surface perturbation profile, (b) spatial frequency spectrum, (c) field enhancement factor, and (d) roughness emittance growth at $50 \mathrm{MV} / \mathrm{m}$. 
TABLE III. Cathode parameters extracted from thermal emittance model fitting.

\begin{tabular}{lc}
\hline \hline Parameter & Value \\
\hline $\begin{array}{l}\text { Work function } \phi_{w} \\
\text { Field enhancement factor } \beta\end{array}$ & $4.16 \pm 0.05 \mathrm{eV}$ \\
Roughness emittance & $1.2 \pm 0.2$ \\
at $50 \mathrm{MV} / \mathrm{m}$ & $0.92 \pm 0.05 \mathrm{~mm} \mathrm{mrad} / \mathrm{mm}$ \\
Thermal emittance due to & $0.57 \pm 0.03 \mathrm{~mm} \mathrm{mrad} / \mathrm{mm}$ \\
excessive photon energy & \\
Thermal emittance due to & $0.44 \pm 0.02 \mathrm{~mm} \mathrm{mrad} / \mathrm{mm}$ \\
Schottky effect at $50 \mathrm{MV} / \mathrm{m}$ & \\
Total emittance at $50 \mathrm{MV} / \mathrm{m}$ & $1.17 \pm 0.05 \mathrm{~mm} \mathrm{mrad} / \mathrm{mm}$ \\
\hline \hline
\end{tabular}

\section{SUMMARY}

This work presents a method to study in situ cathode parameters and surface roughness induced thermal emittance growth without any initial assumption of cathode work function or surface enhancement factor, which is common in other thermal emittance studies $[28,29]$. By measuring the electric field dependence of $\mathrm{QE}$ and thermal emittance, work function, surface enhancement factor, and roughness emittance can be extracted, which not only explains the thermal emittance data but also indicates where the thermal emittance growth comes from. Besides, fitting results can be employed to predict thermal emittance at the higher electric field. This method was implemented on a copper cathode, and reveals a work function of $4.16 \pm 0.05 \mathrm{eV}$, which is much lower than the nominal value of $4.65 \mathrm{eV}$, and a roughness emittance as much as $0.92 \mathrm{~mm} \mathrm{mrad} / \mathrm{mm}$ at $50 \mathrm{MV} / \mathrm{m}$. These values explain a high QE $\left(\sim 1.5 \times 10^{-4}\right)$ and a big thermal emittance for our copper cathode. This method is also applicable for investigating other cathodes whose QE and thermal emittance can be expressed in the form of Eqs. (2) and (15).

The cathode morphology is measured off-line by a white light interferometer, which shows severe surface damages and further explains the big roughness emittance, and a first order analysis of the roughness emittance by Eq. (13) is consistent with the emittance measurement results.

\section{ACKNOWLEDGMENTS}

This work was supported by the National Natural Science Foundation of China (Grant No. 10925523, Grant No. 10735050, and Grant No. 10975088).

[1] B. E. Carlsten, Nucl. Instrum. Methods Phys. Res., Sect. A 285, 313 (1989).

[2] L. Serafini and J. B. Rosenzweig, Phys. Rev. E 55, 7565 (1997).

[3] D. T. Palmer, X. J. Wang, R.H. Miller, M. Babzien, I. Ben-Zvi, C. Pellegrini, J. Sheehan, J. Skaritka,
H. Winick, M. Woodle, and V. Yakimenko, in Proceedings of the Particle Accelerator Conference, Vancouver, BC, Canada, 1997 (IEEE, New York, 1997), p. 2687.

[4] J. Yang, F. Sakai, T. Yanagida, M. Yorozu, Y. Okada, K. Takasago, A. Endo, A. Yada, and M. Washio, J. Appl. Phys. 92, 1608 (2002).

[5] R. Akre, D. Dowell, P. Emma, J. Frisch, S. Gilevich, G. Hays, P. Hering, R. Iverson, C. Limborg-Deprey, H. Loos, A. Miahnahri, J. Schmerge, J. Turner, J. Welch, W. White, and J. Wu, Phys. Rev. ST Accel. Beams 11, 030703 (2008).

[6] Y. Ding, A. Brachmann, F. J. Decker, D. Dowell, P. Emma, J. Frisch, S. Gilevich, G. Hays, P. Hering, Z. Huang, R. Iverson, H. Loos, A. Miahnahri, H. D. Nuhn, D. Ratner, J. Turner, J. Welch, W. White, and J. Wu, Phys. Rev. Lett. 102, 254801 (2009).

[7] P. Emma et al., Nature Photon. 4, 641 (2010).

[8] R. W. Schoenlein, W. P. Leemans, A. H. Chin, P. Volfbeyn, T. E. Glover, P. Balling, M. Zolotorev, K.-J. Kim, S. Chattopadhyay, and C. V. Shank, Science 274, 236 (1996).

[9] P. Musumeci, J.T. Moody, and C.M. Scoby, Ultramicroscopy 108, 1450 (2008).

[10] B.D. Patterson, R. Abela, H. H. Braun, U. Flechsig, R. Ganter, Y. Kim, E. Kirk, A. Oppelt, M. Pedrozzi, S. Reiche, L. Rivkin, T. Schmidt, B. Schmitt, V. N. Strocov, S. Tsujino, and A. F. Wrulich, New J. Phys. 12, 035012 (2010).

[11] J. N. Corlett, B. Austin, K. M. Baptiste, J. M. Byrd, P. Denes, R. J. Donahue, L. R. Doolittle, R. W. Falcone, D. Filippetto, D. S. Fournier, J. Kirz, D. Li, H. A. Padmore, C. F. Papadopoulos, G. C. Pappas, G. Penn, M. Placidi, S. Prestemon, D. Prosnitz, J. Qiang, A. Ratti, M. W. Reinsch, F. Sannibale, D. Schlueter, R. W. Schoenlein, J.W. Staples, T. Vecchione, M. Venturini, R. P. Wells, R. B. Wilcox, J.S. Wurtele, A.E. Charman, E. Kur, and A. Zholents, in Proceedings of the 2011 Particle Accelerator Conference, NY, USA (IEEE, New York, 2011), p. 775.

[12] D. H. Dowell, I. Bazarov, B. Dunham, K. Harkay, C. Hernandez-Garcia, R. Legg, H. Padmore, T. Rao, J. Smedley, and W. Wan, Nucl. Instrum. Methods Phys. Res., Sect. A 622, 685 (2010).

[13] I. V. Bazarov, B. M. Dunham, and C. K. Sinclair, Phys. Rev. Lett. 102, 104801 (2009).

[14] F. Zhou, C. Adolphsen, Y. T. Ding, Z. Li, and A. E. Vlieks, in Proceedings of the IPAC'10 Conference, Kyoto, Japan (ICR, Kyoto, 2010), p. 1761.

[15] X. H. Liu, H. Chen, W.-H. Huang, H. J. Qian, C.-X. Tang, and Z. Zhang, in Proceedings of IPAC'11 (2011), p. 116 [http://accelconf.web.cern.ch/accelconf/IPAC2011/papers/ mopc022.pdf].

[16] C. Limborg-Deprey, C. Adolphsen, T. S. Chu, M.P. Dunning, C. Hast, R. K. Jobe, E. N. Jongewaard, A. E. Vlieks, D. R. Walz, F. Wang, S. G. Anderson, F. V. Hartemann, T.L. Houck, and R.A. Marsh, in Proceedings of the 2011 Particle Accelerator Conference, NY, USA (Ref. [11]), p. 133.

[17] B. Feuerbacher and R. F. Willis, J. Phys. C 9, 169 (1976).

[18] H. J. Qian, J. B. Murphy, Y. Shen, C.X. Tang, and X. J. Wang, Appl. Phys. Lett. 97, 253504 (2010). 
[19] D. Xiang, S.-J. Park, J.-H. Park, Y.-W. Parc, and X.J. Wang, Nucl. Instrum. Methods Phys. Res., Sect. A 562, 48 (2006).

[20] E. Pedersoli, C. M. R. Greaves, W. Wan, C. ColemanSmith, H. A. Padmore, S. Pagliara, A. Cartella, F. Lamarca, G. Ferrini, G. Galimberti, M. Montagnese, S.d. Conte, and F. Parmigiani, Appl. Phys. Lett. 93, 183505 (2008).

[21] T. Tsang, T. Srinivasan-Rao, and J. Fischer, Phys. Rev. B 43, 8870 (1991).

[22] D. H. Dowell and J.F. Schmerge, Phys. Rev. ST Accel. Beams 12, 074201 (2009).

[23] Y. Y. Lau, J. Appl. Phys. 61, 36 (1987).

[24] M. Krasilnikov, in Proceedings of FEL'2006 (2006), p. 583 [http://accelconf.web.cern.ch/accelconf/f06/ PAPERS/THPPH013.PDF].

[25] X. Dao, H. Wen-Hui, D. Ying-Chao, Y. Li-Xin, L. Ren-Kai, T. Chuan-Xiang, L. Yu-Zheng, P. Sung-Ju, and P. Jangho, in Proceedings of PAC'07 (2007), p. 1049 [http://accelconf.web.cern.ch/accelconf/p07/PAPERS/ TUPMN055.PDF].

[26] X.Z. He, C.X. Tang, W. H. Huang and Y.Z. Lin, High Energy Phys. Nucl. Phys. 28, 1007 (2004).

[27] Z. M. Yusof, M. E. Conde, and W. Gai, Phys. Rev. Lett. 93, 114801 (2004).

[28] C.P. Hauri, R. Ganter, F. Le Pimpec, A. Trisorio, C. Ruchert, and H.H. Braun, Phys. Rev. Lett. 104, 234802 (2010).

[29] W. S. Graves, L. F. DiMauro, R. Heese, E. D. Johnson, J. Rose, J. Rudati, T. Shaftan, and B. Sheehy, in Proceedings of the 19th Particle Accelerator Conference, Chicago, Illinois, 2001 (IEEE, Piscataway, NJ, 2001), p. 2230 [http://accelconf.web.cern.ch/accelconf/p01/ PAPERS/WPAH059.PDF].

[30] D. J. Bradley, M. B. Allenson, and B. R. Holeman, J. Phys. D 10, 111 (1977).
[31] C. Tang, W. Huang, R. Li, Y. Du, L. Yan, J. Shi, Q. Du, P. Yu, H. Chen, T. Du, C. Cheng, and Y. Lin, Nucl. Instrum. Methods Phys. Res., Sect. A 608, S70 (2009).

[32] D. Xiang, Y.-C. Du, L.-X. Yan, R.-K. Li, W.-H. Huang, C.-X. Tang, and Y.-Z. Lin, Phys. Rev. ST Accel. Beams 12, 022801 (2009).

[33] K.-J. Kim, Nucl. Instrum. Methods Phys. Res., Sect. A 275, 201 (1989).

[34] J. W. Wang and G. A. Loew, Report No. SLAC-PUB-7684, 1997.

[35] http://www.desy.de/ mpyflo/.

[36] http://www.andor.com.

[37] D. H. Dowell, F. K. King, R. E. Kirby, J. F. Schmerge, and J. M. Smedley, Phys. Rev. ST Accel. Beams 9, 063502 (2006).

[38] A. Brachmann, F.-J. Decker, P. Emma, R. H. Iverson, P. Stefan, J.L. Turner, and F. Zhou, in Proceedings of IPAC'11 (2011), p. 3200 [http://accelconf.web.cern.ch/ accelconf/IPAC2011/papers/thpc134.pdf].

[39] X. J. Wang, M. Babzien, R. Malone, and Z. Wu, in Proceedings of LINAC02 (2002), p. 142 [http://accelconf .web.cern.ch/accelconf/102/PAPERS/MO445.PDF].

[40] O. Renault, R. Brochier, A. Roule, P. H. Haumesser, B. Krömker, and D. Funnemann, Surf. Interface Anal. 38, 375 (2006).

[41] R. G. E, Surf. Sci. 68, 20 (1977).

[42] H. Loos, Mini-workshop on Characterization of High-Brightness Electron Beam, DESY-Zeuthen, 2008.

[43] A. Brachmann, F. J. Decker, Y. Ding, D. Dowell, P. Emma, J. Frisch, A. Gilevich, G. Hays, P. Hering, Z. Huang, R. Iverson, H. Loos, A. Miahnahri, H.-D. N. Nordlund, P. A. Pianetta, J. Turner, J. Welch, W. E. White, J. Wu, and D. Xiang, in Proceedings of the IPAC'10 Conference, Kyoto, Japan (Ref. [14]), p. 2284. 